\title{
Risk prevention of different forms of gestational diabetes mellitus based on energy metabolism prior to diagnosis
}

\author{
Jiayu Lu ${ }^{\mathrm{a}, 1}$, Hongqing Jiang ${ }^{\mathrm{b}, 1}$, Song Zhang ${ }^{\mathrm{a}}$, Yimin Yang ${ }^{\mathrm{a}}$, Dongmei Hao ${ }^{\mathrm{a}}$, Xuwen $\mathrm{Li}^{\mathrm{a}}$, \\ Aiqing Chen ${ }^{\mathrm{c}}$, Jing Shao ${ }^{\mathrm{c}}$, Xiaohong $\mathrm{Liu}^{\mathrm{c}}$ and Lin Yang, ${ }^{\mathrm{a}, *}$ \\ ${ }^{a}$ Faculty of Environment and Life Sciences, Beijing University of Technology, Intelligent Physiological \\ Measurement and Clinical Translation, Beijing International Base for Scientific and Technological \\ Cooperation, Beijing, China \\ ${ }^{\mathrm{b}}$ Haidian Maternal and Children Health Hospital, Beijing, China \\ ${ }^{\mathrm{c}}$ Beijing Yes Medical Devices Co. Ltd., Beijing, China
}

\begin{abstract}
.
BACKGROUND: Gestational diabetes mellitus (GDM) is a metabolic disease that seriously endangers the health of mothers and children. It is important to monitor GDM in real-time before diagnosis and to prevent it effectively.

OBJECTIVE: GDM was divided into the second trimester diagnosed diabetes mellitus (GDM_24) and the third trimester diagnosed diabetes mellitus (GDM_30). The risk prediction of two types of GDM was performed in normal pregnant women at 11-13 and 16-19 weeks of pregnancy, respectively.

METHODS: By stages, the K-W test was used to analyze the differences between basic information and energy metabolism factors, and multiple logistic regression was used to analyze the risk of energy metabolism factors and to correct the confounders with significant differences.

RESULTS: For the GDM_24 group, each additional unit of oxygen consumption $\left(\mathrm{VO}_{2}\right)$, carbon dioxide production, and resting energy expenditure (REE) increased the risk by $2.4 \%, 3.5 \%, 0.4 \%$, and $2.1 \%, 2.6 \%$, and $0.3 \%$, respectively, at $11-13$ and $16-19$ weeks of pregnancy. For the GDM_30 group, each additional unit of $\mathrm{VO}_{2}$ and REE was associated with an increased risk of $2.3 \%$ and $0.3 \%$, respectively, at $16-19$ weeks of pregnancy.

CONCLUSION: The risk of GDM_30 only appeared in pregnant women during 16-19 weeks of pregnancy, which may indicate that GDM_24 and GDM_30 have different pathogenesis.
\end{abstract}

Keywords: Diabetes mellitus in the second trimester, diagnosis of diabetes mellitus in the third trimester, energy metabolism

\section{Introduction}

Gestational diabetes mellitus (GDM) during pregnancy is the most common metabolic disorder, it is defined as the start or during the pregnancy for the first time found that glucose intolerance [1]. According to the diagnostic criteria of GDM proposed by the International Association for the Study of Diabetes

\footnotetext{
${ }^{1}$ Jiayu Lu and Hongqing Jiang are the co-first authors.

${ }^{*}$ Corresponding author: Lin Yang, Faculty of Environment and Life Sciences, Beijing International Science and Technology Cooperation Base for Intelligent Physiological Measurement and Clinical Transformation, Beijing 100124, China. Tel.: +86 13426181228; E-mail: yanglin@bjut.edu.cn.
}

0928-7329 (C) 2022 - The authors. Published by IOS Press. This is an Open Access article distributed under the terms of the Creative Commons Attribution-NonCommercial License (CC BY-NC 4.0). 
and Pregnancy (IADPSG), oral glucose tolerance test (OGTT) is carried out for all pregnant women at 24-28 weeks of pregnancy [2]. Some Chinese hospitals will carry out the second OGTT for all pregnant women after 30 weeks of pregnancy under this standard. Due to stricter screening, the incidence of OGTT has increased rapidly in recent years, reaching 22.3\% in 2017 [3]. Due to higher insulin resistance in GDM, said its adverse metabolic characteristics, at the same time, also have a higher risk of adverse pregnancy outcomes [4-6], which cause serious damage to the life of the maternal and fetal health and safety. This study hypothesizes that the pathogenesis of gestational diabetes is different in different stages of diagnosis. Therefore, according to the different diagnosis times of GDM, it is divided into pregnant women diagnosed with diabetes in the second trimester and the third trimester. In the perspective of energy metabolism before the inquiry on the diagnosis of GDM pregnant women for effective risk prevention, to reduce the prevalence of GDM.

\section{Materials and methods}

\subsection{Background, population, exclusion, and inclusion criteria}

From July 2018 to May 2019, a total of 168 pregnant women who underwent routine prenatal examination (file establishment) and delivered in the high-risk outpatient department of Maternal and Child Health Hospital of Haidian District, Beijing, were randomly recruited as the research subjects. All subjects were excluded by inclusion and exclusion criteria, and the study was established after obtaining informed consent. The energy metabolism of the pregnant women was measured and followed up at 11-13 weeks of pregnancy and 16-19 weeks of pregnancy from the establishment of the file, and the epidemiological parameters of the changes during pregnancy were recorded. According to the two OGTT diagnosis results, pregnant women were divided into normal pregnant women (normal group), pregnant women diagnosed with diabetes in the second trimester (GDM_24 group), and pregnant women diagnosed with diabetes in the third trimester (GDM_30 group).

Inclusion criteria: (1) single pregnancy; (2) regular menstrual cycles; (3) fetal development is consistent with the gestation period; (4) No cardiovascular disease, chronic hypertension, diabetes, anemia, and normal liver and kidney function before pregnancy; (5) thyroid function is normal, and there is no obvious acute or chronic infection and other obstetric complications.

Exclusion criteria: (1) multiple pregnancy; (2) complications of pregnancy, fetal malformation, and thyroid dysfunction during pregnancy; (3) During the measurement of energy metabolism parameters, the data were inaccurate due to objective problems such as mask leakage and shortness of breath caused by physical discomfort of pregnant women; (4) Transfer halfway.

\subsection{Data collection}

\subsubsection{Physical measurement}

Height and weight were recorded pre-pregnancy, 11-13 weeks, and 16-19 weeks. Body mass index (BMI) and body surface area (SA) were calculated at each stage. The body surface area was calculated by the Stevenson formula [7].

\subsubsection{Energy metabolic measurement}

Energy metabolism was measured with indirect energy measurement instrument (Breezing ${ }^{\mathrm{TM}}$, USA). It's used to measure resting energy expenditure (REE), Respiratory quotient (RQ), oxygen consumption 
Table 1

Basic information of pregnant women at 11-13 weeks of pregnancy

\begin{tabular}{lcccc}
\hline & Normal group & GDM_24 group & GDM_30 group & $P$ \\
\hline $\mathrm{N}$ & 52 & 21 & 29 & - \\
Age $($ years $)$ & $30.38 \pm 4.13$ & $30.95 \pm 3.67$ & $29.72 \pm 2.66$ & 0.615 \\
Height $(\mathrm{m})$ & $1.62 \pm 0.05$ & $1.63 \pm 0.05$ & $1.62 \pm 0.04$ & 0.379 \\
Pre-pregnancy weight $(\mathrm{kg})^{*}$ & $54.04 \pm 7.28$ & $59.90 \pm 8.69$ & $56.21 \pm 7.51$ & 0.039 \\
Pre-pregnancy BMI $\left(\mathrm{kg} / \mathrm{m}^{2}\right)^{*}$ & $20.57(18.74,22.10)$ & $22.07(20.08,23.99)$ & $21.30(19.69,23.10)$ & 0.049 \\
${\text { Weight }(\mathrm{kg})^{*}}_{\mathrm{BMI}\left(\mathrm{kg} / \mathrm{m}^{2}\right)^{*}}^{54.25 \pm 7.17}$ & $61.19 \pm 9.52$ & $56.97 \pm 7.35$ & 0.014 \\
$\mathrm{GWG}(\mathrm{kg})$ & $20.59 \pm 2.33$ & $22.98 \pm 3.60$ & $21.82 \pm 2.68$ & 0.018 \\
$\Delta \mathrm{BMI}\left(\mathrm{kg} / \mathrm{m}^{2}\right)$ & $0.00(0.00,1.00)$ & $0.00(0.00,2.00)$ & $0.00(0.00,2.00)$ & 0.186 \\
History of spontaneous abortion, $n$ yes $(\%)$ & $0.00(0.00,0.39)$ & $0.00(0.00,0.85)$ & $0.00(0.00,0.76)$ & 0.205 \\
Family history of diabetes, $n$ yes $(\%)$ & $14(26.9 \%)$ & $4(19 \%)$ & $13(44.8 \%)$ & 0.114 \\
\hline
\end{tabular}

When a variable is normally distributed, data are listed as mean ( \pm standard deviation). In cases of non-normal distribution, data are listed as median (interquartile range). Qualitative variables are expressed as $n(\%)$. BMI, body mass index; GWG, gestational weight gain; $\triangle \mathrm{BMI}$, gestational BMI gain. ${ }^{*} P<0.05$ in the three groups and $P<0.05$ in the normal group and GDM_24 group.

Table 2

Energy metabolism information and differences of the normal group, GDM_24 group and GDM_30 group at 11-13 weeks pregnancy

\begin{tabular}{|c|c|c|c|c|}
\hline & Normal group & GDM_24 group & GDM_30 group & $P$ \\
\hline RQ & $0.71 \pm 0.02$ & $0.72 \pm 0.03$ & $0.72 \pm 0.03$ & 0.508 \\
\hline $\mathrm{VO}_{2}(\mathrm{ml} / \mathrm{min})^{*}$ & $218.20 \pm 32.67$ & $239.77 \pm 33.10$ & $223.10 \pm 22.30$ & 0.047 \\
\hline $\mathrm{VO}_{2} / \mathrm{kg}(\mathrm{ml} / \mathrm{kg} / \mathrm{min})$ & $4.07 \pm 0.68$ & $3.95 \pm 0.42$ & $3.96 \pm 0.50)$ & 0.817 \\
\hline $\mathrm{VCO}_{2}(\mathrm{ml} / \mathrm{min})$ & $155.39 \pm 23.22$ & $172.76 \pm 27.21$ & $160.04 \pm 16.15$ & 0.056 \\
\hline $\operatorname{REE}(\mathrm{kcal} / \mathrm{d})^{*}$ & $1471.60 \pm 219.54$ & $1620.28 \pm 227.69$ & $1508.07 \pm 149.38$ & 0.049 \\
\hline REE/kg (kcal/kg/d) & $27.45 \pm 4.61$ & $26.68 \pm 2.85$ & $26.74 \pm 3.26$ & 0.817 \\
\hline $\operatorname{RMR}(\mathrm{kcal} / \mathrm{d})$ & $962.89 \pm 137.06$ & $993.87 \pm 84.49$ & $966.96 \pm 90.00$ & 0.422 \\
\hline RMR/kg (kcal/kg/d) & $18.12 \pm 3.87$ & $16.56 \pm 2.64$ & $17.28 \pm 2.91$ & 0.243 \\
\hline FOX (mg/min) & $107.06(90.65,115.36)$ & $113.22(100.95,121.56)$ & $103.09(91.03,116.91)$ & 0.199 \\
\hline $\mathrm{FOX}_{\mathrm{REE}}(\mathrm{mg})$ & $105.49(95.73,108.44)$ & $100.95(91.17,108.45)$ & $100.24(95.14,108.80)$ & 0.512 \\
\hline $\mathrm{FOX}_{\mathrm{RMR}}(\mathrm{mg})$ & $163.70(141.14,171.31)$ & $160.82(154.02,172.06)$ & $158.25(145.67,168.73)$ & 0.557 \\
\hline $\operatorname{COX}(\mathrm{mg} / \mathrm{min})$ & $-0.77(-7.12,21.78)$ & $12.71(-9.59,38.83)$ & $13.18(-9.23,24.65)$ & 0.414 \\
\hline $\mathrm{COX}_{\mathrm{REE}}(\mathrm{mg})$ & $-0.800(-8.27,24.12)$ & $10.85(-8.37,35.70)$ & $12.59(-9.18,25.55)$ & 0.505 \\
\hline $\mathrm{COX}_{\mathrm{RMR}}(\mathrm{mg})$ & $-1.33(-12.26,33.12)$ & $17.09(-13.17,56.79)$ & $18.99(-14.24,40.71)$ & 0.441 \\
\hline
\end{tabular}

$\mathrm{RQ}$, respiratory quotient, $\mathrm{REE}$, rest energy expenditure; $\mathrm{VO}_{2}$, oxygen consumption rate; $\mathrm{VCO}_{2}$, carbon dioxide production rate; RMR, relative metabolic rate; FOX and COX, contribution of substrate oxidation (carbohydrate and fat, respectively) to the overall energetic metabolism; FOX $\mathrm{REE}_{\text {and }}$ FOX $\mathrm{RMR}_{\mathrm{R}}$, the amount of fat oxidized per 1kal REE or RMR consumed; FOX $\mathrm{REE}_{\mathrm{RE}}$ and FOX $_{\mathrm{RMR}}$, the amount of carbohydrate oxidized per $1 \mathrm{kal}$ REE or RMR consumed. ${ }^{*} P<0.05$ in the three groups and $P<0.05$ in the normal group and GDM_24 group.

$\left(\mathrm{VO}_{2}\right)$ and carbon dioxide production $\left(\mathrm{VCO}_{2}\right)$. Basal metabolic rate (RMR) can be calculated by REE and SA. Carbohydrate oxidation and lipid oxidation were obtained by the Fryan formula [8].

The energy metabolism parameters meet the following conditions: (1) fasting for 12 hours; (2) Sit quietly for 30 minutes before measurement; (3) No vigorous exercise and no caffeine intake within 12 hours; (4) The room temperature should be kept at about $25^{\circ} \mathrm{C}$ to ensure that the subject will not lose heart or heat.

\subsubsection{Statistical analysis}

In this study, SPSS 20.0 software was used for statistical analysis of the data. In the basic analysis of data, independent variables are divided into quantitative parameters and qualitative parameters. For 
Table 3

Risk analysis of energy metabolism of the normal group, GDM_24 group and GDM_30 group at 11-13 weeks pregnancy

\begin{tabular}{|c|c|c|c|c|c|c|c|}
\hline & & \multicolumn{3}{|l|}{ Univariate analysis } & \multicolumn{3}{|c|}{ Adjusted for epidemiology } \\
\hline & & OR $(95 \% \mathrm{CI})$ & $\beta$ & $P$ & OR $(95 \% \mathrm{CI})$ & $\beta$ & $P$ \\
\hline \multirow[t]{2}{*}{$\mathrm{VO}_{2}(\mathrm{ml} / \mathrm{min})$} & GDM_24* & $1.024(1.006,1.043)$ & 0.024 & 0.010 & $1.016(0.996,1.037)$ & 0.016 & 0.108 \\
\hline & GDM_30 & $1.006(0.991,1.022)$ & 0.006 & 0.450 & $1.003(0.986,1.019)$ & 0.003 & 0.763 \\
\hline \multirow{2}{*}{$\mathrm{VO}_{2} / \mathrm{kg}(\mathrm{ml} / \mathrm{kg} / \mathrm{min})$} & GDM_24 & $0.699(0.288,1.695)$ & -0.359 & 0.428 & $2.022(0.630,6.484)$ & 0.704 & 0.236 \\
\hline & GDM_30 & $0.729(0.330,1.609)$ & -0.316 & 0.434 & $1.313(0.492,3.503)$ & 0.272 & 0.587 \\
\hline \multirow[t]{2}{*}{$\mathrm{VCO}_{2}(\mathrm{ml} / \mathrm{min})$} & GDM_24* & $1.035(1.010,1.061)$ & 0.035 & 0.006 & $1.025(0.997,1.053)$ & 0.025 & 0.075 \\
\hline & GDM_30 & $1.010(0.989,1.031)$ & 0.010 & 0.359 & $1.006(0.983,1.029)$ & 0.006 & 0.616 \\
\hline \multirow[t]{2}{*}{$\operatorname{REE}(\mathrm{kcal} / \mathrm{d})$} & GDM_24* & $1.004(1.000,1.006)$ & 0.004 & 0.008 & $1.002(1.000,1.005)$ & 0.002 & 0.100 \\
\hline & GDM_30 & $1.001(0.999,1.003)$ & 0.001 & 0.433 & $1.000(0.998,1.003)$ & 0.000 & 0.738 \\
\hline \multirow[t]{2}{*}{ REE/kg (kcal/kg/d) } & GDM_24 & $0.950(0.833,1.085)$ & -0.051 & 0.451 & $1.115(0.937,1.327)$ & 0.109 & 0.291 \\
\hline & GDM_30 & $8,1.074)$ & -0.046 & 0.441 & $1.043(0.901,1.2$ & 0.042 & 0.570 \\
\hline \multirow[t]{2}{*}{$\operatorname{RMR}(\mathrm{kcal} / \mathrm{d})$} & GDM_24 & $1.002(0.998,1.007)$ & 0.002 & 0.298 & $1.003(0.998,1.008)$ & 0.003 & 0.181 \\
\hline & GDM_30 & 1.000( & 0.000 & 0.878 & $7,1.005)$ & 0.001 & 0.579 \\
\hline \multirow[t]{2}{*}{ RMR/kg (kcal/kg/d) } & GDM_24 & $0.864(0.733,1.019)$ & -0.146 & 0.083 & $1.091(0.862,1.380)$ & 0.087 & 0.470 \\
\hline & GDM_30 & $09,1.056)$ & -0.074 & 0.290 & $73,1.297)$ & 0.062 & 0.539 \\
\hline \multirow[t]{2}{*}{ FOX (mg/min) } & GDM_24 & $1.026(0.994,1.058)$ & 0.025 & 0.112 & $1.014(0.981,1.049)$ & 0.014 & 0.397 \\
\hline & GDM_30 & $1.003(0.976,1.031)$ & 0.003 & 0.812 & $0.998(0.970,1.027)$ & -0.002 & 0.879 \\
\hline \multirow[t]{2}{*}{$\mathrm{FOX}_{\mathrm{REE}}(\mathrm{mg})$} & GDM_24 & $0.970(0.917,1.026)$ & -0.031 & 0.286 & $0.975(0.918,1.036)$ & -0.025 & 0.418 \\
\hline & GDM_30 & $0.980(0.932,1.031)$ & -0.020 & 0.444 & $0.979(0.928,1.033)$ & -0.021 & 0.440 \\
\hline \multirow[t]{2}{*}{$\mathrm{FOX}_{\mathrm{RMR}}(\mathrm{mg})$} & GDM_24 & $1.021(0.988,1.056)$ & 0.021 & 0.207 & $0.993(0.957,1.031)$ & -0.007 & 0.725 \\
\hline & GDM_30 & $1.001(0.973,1.029)$ & 0.001 & 0.955 & $0.982(0.951,1.015)$ & -0.018 & 0.280 \\
\hline \multirow[t]{2}{*}{$\mathrm{COX}(\mathrm{mg} / \mathrm{min})$} & GDM_24 & $1.016(0.995,1.037)$ & 0.016 & 0.130 & $1.012(0.990,1.035)$ & 0.012 & 0.286 \\
\hline & GDM_30 & $1.008(0.989,1.027)$ & 0.008 & 0.426 & $1.008(0.988,1.028)$ & 0.008 & 0.452 \\
\hline \multirow[t]{2}{*}{$\mathrm{COX}_{\mathrm{REE}}(\mathrm{mg})$} & GDM_24 & $1.012(0.990,1.035)$ & 0.012 & 0.286 & $1.010(0.986,1.034)$ & 0.010 & 0.418 \\
\hline & GDM_30 & $1.008(0.988,1.028)$ & 0.008 & 0.442 & $1.008(0.987,1.030)$ & 0.008 & 0.438 \\
\hline \multirow[t]{2}{*}{$\mathrm{COX}_{\mathrm{RMR}}(\mathrm{mg})$} & GDM_24 & $1.009(0.995,1.023)$ & 0.009 & 0.206 & $1.007(0.992,1.022)$ & 0.007 & 0.380 \\
\hline & GDM_30 & $1.006(0.993,1.019)$ & 0.016 & 0.351 & $1.006(0.993,1.020)$ & 0.006 & 0.379 \\
\hline
\end{tabular}

$\mathrm{RQ}$, respiratory quotient, $\mathrm{REE}$, rest energy expenditure; $\mathrm{VO}_{2}$, oxygen consumption rate; $\mathrm{VCO}_{2}$, carbon dioxide production rate; RMR, relative metabolic rate; FOX and COX, contribution of substrate oxidation (carbohydrate and fat, respectively) to the overall energetic metabolism; FOX REE $_{\text {and FOX }}$ RMR, the amount of fat oxidized per 1kal REE or RMR consumed; FOX REE $_{\text {and }}$ $\mathrm{FOX}_{\mathrm{RMR}}$, the amount of carbohydrate oxidized per 1 kal REE or RMR consumed. Epidemiology included BMI before pregnancy and $\mathrm{BMI}$ at 11 to 13 weeks of pregnancy. ${ }^{*} P<0.05$ in the univariate analysis.

quantitative parameters, normality and homogeneity of variance were tested for each group of data. Mean \pm standard deviation was calculated if the data met the standard, and median (interquartile range) was used if the data did not meet the standard. For qualitative parameters, the non-parametric chi-square test was used to analyze the different distribution of parameters in the normal group, GDM_24 group, and GDM_30 group.

In the exploration of each stage, the differences of basic information and energy metabolism between the three groups of pregnant women were first analyzed by Kruskal-Wallis (K-W) test. By multiple logistic regression analysis GDM_24 before the diagnosis of GDM group and GDM_30 group compared with the normal group in the aspect of energy metabolism of risks, if there are mixed in the underlying information factor $(P<0.05)$ will be in the risk analysis on the correction to ensure GDM_24 group and GDM_30 energy metabolism parameters have the relatively independent risk for the normal group.

\section{Results}

The basic information of 102 subjects at 11-13 weeks pregnancy is shown in Table 1, including 52 in the normal group, 21 in the GDM_24 group, and 19 in the GDM_30 group. According to the analysis, 
Table 4

Basic information of pregnant women at 16-19 weeks of pregnancy

\begin{tabular}{lcccc}
\hline & Normal group & GDM_24 group & GDM_30 group & $P$ \\
\hline $\mathrm{N}$ & 44 & 26 & 26 & - \\
Age $($ years $)$ & $31.00(28.00,34.00)$ & $29.50(27.00,32.25)$ & $28.00(27.75,31.00)$ & 0.143 \\
Height $(\mathrm{m})$ & $1.62 \pm 0.0 .5$ & $1.64 \pm 0.05$ & $1.62 \pm 0.04$ & 0.531 \\
Pre-pregnancy weight $(\mathrm{kg})^{*}$ & $54.30 \pm 6.01$ & $58.69 \pm 8.60$ & $57.37 \pm 8.43$ & 0.094 \\
Pre-pregnancy BMI $\left(\mathrm{kg} / \mathrm{m}^{2}\right)^{*}$ & $20.65 \pm 2.06$ & $21.93 \pm 3.05$ & $21.80 \pm 3.10$ & 0.217 \\
Weight $(\mathrm{kg})^{*}$ & $56.75 \pm 5.92$ & $61.57 \pm 9.64$ & $60.88 \pm 9.05$ & 0.085 \\
$\mathrm{BMI}\left(\mathrm{kg} / \mathrm{m}^{2}\right)^{*}$ & $20.59 \pm 2.33$ & $22.98 \pm 3.60$ & $21.82 \pm 2.68$ & 0.119 \\
$\mathrm{GWG}(\mathrm{kg})$ & $2.00(1.25,1.00)$ & $2.75(1.00,4.00)$ & $3.25(1.08,5.63)$ & 0.487 \\
$\Delta$ BMI $\left(\mathrm{kg} / \mathrm{m}^{2}\right)$ & $21.75(20.13,22.89)$ & $22.28(20.63,24.71)$ & $21.98(20.61,25.64)$ & 0.476 \\
History of spontaneous abortion, $n$ yes $(\%)$ & $15(34.1 \%)$ & $7(26.9 \%)$ & $11(42.3 \%)$ & 0.508 \\
Family history of diabetes, $n$ yes $(\%)$ & $3(6.8 \%)$ & $4(15.4 \%)$ & $4(15.4 \%)$ & 0.426 \\
\hline
\end{tabular}

When a variable is normally distributed, data are listed as mean ( \pm standard deviation). In cases of non-normal distribution, data are listed as median (interquartile range). Qualitative variables are expressed as $n(\%)$. BMI, body mass index; GWG, gestational weight gain; $\triangle \mathrm{BMI}$, gestational BMI gain.

Table 5

Energy metabolism information and differences of the normal group, GDM_24 group and GDM_30 group at 16-19 weeks pregnancy

\begin{tabular}{|c|c|c|c|c|}
\hline & Normal group & GDM_24 group & GDM_30 group & $P$ \\
\hline RQ & $0.71(0.69,0.72)$ & $0.70(0.68,0.73)$ & $0.70(0.68,0.73)$ & 0.991 \\
\hline $\mathrm{VO}_{2}(\mathrm{ml} / \mathrm{min})^{*}$ & $222.57 \pm 24.76$ & $237.95 \pm 31.99$ & $236.69 \pm 22.07$ & 0.023 \\
\hline $\mathrm{VO}_{2} / \mathrm{kg}(\mathrm{ml} / \mathrm{kg} / \mathrm{min})$ & $3.95(3.67,4.16)$ & $3.82(3.50,4.35)$ & $3.78(3.47,4.52)$ & 0.930 \\
\hline $\mathrm{VCO}_{2}(\mathrm{ml} / \mathrm{min})$ & $156.08 \pm 16.65$ & $167.12 \pm 22.27$ & $165.68 \pm 17.63$ & 0.043 \\
\hline $\operatorname{REE}(\mathrm{kcal} / \mathrm{d})^{*}$ & $1497.23 \pm 164.57$ & $1598.50 \pm 219.51$ & $1591.58 \pm 149.67$ & 0.022 \\
\hline REE/kg (kcal/kg/d) & $26.57(24.64,27.87)$ & $25.68(34.48,29.42)$ & $25.24(23.28,30.6)$ & 0.899 \\
\hline RMR (kcal/d) & $958.40 \pm 90.57$ & $987.12 \pm 133.88$ & $987.49 \pm 91.30$ & 0.538 \\
\hline RMR/kg (kcal/kg/d) & $17.07 \pm 2.50$ & $16.42 \pm 4.01$ & $16.64 \pm 3.34$ & 0.398 \\
\hline FOX (mg/min) & $111.03 \pm 16.34$ & $118.28 \pm 24.02$ & $118.55 \pm 16.34$ & 0.152 \\
\hline $\mathrm{FOX}_{\text {REE }}(\mathrm{mg})$ & $106.56 \pm 7.81$ & $106.35 \pm 13.90$ & $107.35 \pm 12.43$ & 0.996 \\
\hline $\mathrm{FOX}_{\mathrm{RMR}}(\mathrm{mg})$ & $166.46 \pm 15.22$ & $173.58 \pm 27.16$ & $173.34 \pm 22.89$ & 0.534 \\
\hline $\mathrm{COX}(\mathrm{mg} / \mathrm{min})$ & $-4.26 \pm 21.26$ & $-3.41 \pm 40.55$ & $-5.85 \pm 34.60$ & 0.998 \\
\hline $\mathrm{COX}_{\mathrm{REE}}(\mathrm{mg})$ & $-3.54 \pm 19.91$ & $-2.33 \pm 34.53$ & $-5.52 \pm 31.67$ & 0.997 \\
\hline $\mathrm{COX}_{\mathrm{RMR}}(\mathrm{mg})$ & $-5.43 \pm 30.8$ & $-3.76 \pm 58.30$ & $-8.61 \pm 50.06$ & 0.993 \\
\hline
\end{tabular}

$\mathrm{RQ}$, respiratory quotient, REE, rest energy expenditure; $\mathrm{VO}_{2}$, oxygen consumption rate; $\mathrm{VCO}_{2}$, carbon dioxide production rate; RMR, relative metabolic rate; FOX and COX, contribution of substrate oxidation (carbohydrate and fat, respectively) to the overall energetic metabolism; FOX $_{\text {REE }}$ and FOX RMR $_{\text {, the amount of fat oxidized per } 1 \mathrm{kal} \text { REE or RMR consumed; FOX }}$ REE and FOX $_{\text {RMR }}$, the amount of carbohydrate oxidized per 1 kal REE or RMR consumed. ${ }^{*} P<0.05$ in the three groups and $P<0.05$ in the normal group and GDM_24 group. ${ }^{* *} P<0.05$ in the three groups and $P<0.05$ in the normal group and GDM_30 group.

result shows that three sets of pre-pregnancy weight and BMI, 11-13 weeks of pregnancy weight and BMI have a significant difference, comparing two found in the normal group and GDM_24 pre-pregnancy weight $(P=0.011)$ and BMI $(P=0.019), 11-13$ weeks of pregnancy weight $(P=0.004)$ and BMI $(P=0.008)$ are different. After correction by Bonferroni method, pregnancy weight $(P=0.034)$, weight $(P=0.011)$ and BMI $(P=0.023)$ at $11-13$ weeks of pregnancy still have difference. In consideration of the practical significance and collinearity that BMI was more accurate than body weight in the clinical analysis, BMI before pregnancy and BMI at 11-13 weeks of pregnancy with significant differences between the three groups were selected and corrected in the subsequent risk analysis.

The energy metabolism information and differences of the normal group, GDM_24 group, and GDM_30 
Table 6

Risk analysis of energy metabolism of the normal group, GDM_24 group and GDM_30 group at 16-19 weeks pregnancy

\begin{tabular}{|c|c|c|c|c|}
\hline & \multicolumn{3}{|c|}{ Univariate analysis } & \\
\hline & OR $(95 \% \mathrm{CI})$ & $\beta$ & $P$ & \\
\hline \multirow{2}{*}{$\mathrm{VO}_{2}(\mathrm{ml} / \mathrm{min})$} & GDM_24* & $1.023(1.003,1.044)$ & 0.023 & 0.025 \\
\hline & GDM_30* & $1.021(1.001,1.041)$ & 0.021 & 0.038 \\
\hline \multirow{2}{*}{$\mathrm{VO}_{2} / \mathrm{kg}(\mathrm{ml} / \mathrm{kg} / \mathrm{min})$} & GDM_24 & $0.976(0.393,2.423)$ & -0.024 & 0.959 \\
\hline & GDM_30 & $1.020(0.412,2.526)$ & 0.020 & 0.966 \\
\hline \multirow[t]{2}{*}{$\mathrm{VCO}_{2}(\mathrm{ml} / \mathrm{min})$} & GDM_24* & $1.034(1.005,1.063)$ & 0.033 & 0.021 \\
\hline & GDM_30* & $1.026(1.001,1.058)$ & 0.029 & 0.042 \\
\hline \multirow[t]{2}{*}{ REE (kcal/d) } & GDM_24* & $1.003(1.000,1.006)$ & 0.003 & 0.028 \\
\hline & GDM_30* & $1.003(1.000,1.006)$ & 0.003 & 0.040 \\
\hline \multirow[t]{2}{*}{ REE/kg (kcal/kg/d) } & GDM_24 & 0.992(0.865,1.137) & -0.008 & 0.907 \\
\hline & GDM_30 & $1.002(0.874,1.148)$ & 0.002 & 0.979 \\
\hline \multirow[t]{2}{*}{ RMR (kcal/d) } & GDM_24 & $1.002(0.997,1.007)$ & 0.002 & 0.361 \\
\hline & GDM_30 & $1.003(0.998,1.008)$ & 0.003 & 0.258 \\
\hline \multirow[t]{2}{*}{$\mathrm{RMR} / \mathrm{kg}(\mathrm{kcal} / \mathrm{kg} / \mathrm{d})$} & GDM_24 & $0.936(0.799,1.095)$ & -0.066 & 0.409 \\
\hline & GDM_30 & $0.957(0.820,1.117)$ & -0.044 & 0.581 \\
\hline \multirow[t]{2}{*}{ FOX (mg/min) } & GDM_24 & $1.022(0.995,1.050)$ & 0.022 & 0.118 \\
\hline & GDM_30 & $1.023(0.995,1.051)$ & 0.022 & 0.105 \\
\hline \multirow[t]{2}{*}{$\mathrm{FOX}_{\mathrm{REE}}(\mathrm{mg})$} & GDM_24 & $0.998(0.954,1.044)$ & -0.002 & 0.937 \\
\hline & GDM_30 & $1.007(0.963,1.052)$ & 0.007 & 0.770 \\
\hline \multirow[t]{2}{*}{$\mathrm{FOX}_{\mathrm{RMR}}(\mathrm{mg})$} & GDM_24 & $1.017(0.993,1.041)$ & 0.017 & 0.168 \\
\hline & GDM_30 & $1.016(0.992,1.041)$ & 0.016 & 0.181 \\
\hline \multirow{2}{*}{$\mathrm{COX}(\mathrm{mg} / \mathrm{min})$} & GDM_24 & $1.001(0.985,1.017)$ & 0.001 & 0.911 \\
\hline & GDM_30 & $0.998(0.983,1.014)$ & -0.002 & 0.835 \\
\hline \multirow[t]{2}{*}{$\mathrm{COX}_{\mathrm{REE}}(\mathrm{mg})$} & GDM_24 & 1.002(0.984,1.020) & 0.002 & 0.858 \\
\hline & GDM_30 & 0.997(0.980,1.015) & -0.003 & 0.771 \\
\hline \multirow[t]{2}{*}{$\mathrm{COX}_{\mathrm{RMR}}(\mathrm{mg})$} & GDM_24 & $1.001(0.990,1.012)$ & 0.001 & 0.878 \\
\hline & GDM_30 & 0.998(0.988,1.009) & -0.002 & 0.772 \\
\hline
\end{tabular}

$\mathrm{RQ}$, respiratory quotient, $\mathrm{REE}$, rest energy expenditure; $\mathrm{VO}_{2}$, oxygen consumption rate; $\mathrm{VCO}_{2}$, carbon dioxide production rate; RMR, relative metabolic rate; FOX and $\mathrm{COX}$, contribution of substrate oxidation (carbohydrate and fat, respectively)

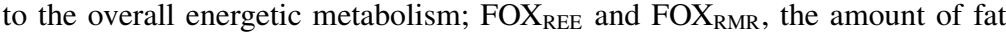
oxidized per 1kal REE or RMR consumed; FOX $\mathrm{REE}_{\mathrm{R}}$ and FOX $\mathrm{FMR}_{\mathrm{R}}$, the amount of carbohydrate oxidized per 1kal REE or RMR consumed. Epidemiology included BMI before pregnancy and BMI at 11 to 13 weeks of pregnancy. ${ }^{*} P<0.05$ in the univariate analysis.

group at 11-13 weeks of pregnancy are shown in Table 2. According to the results of statistical analysis, there were significant differences in $\mathrm{VO}_{2}$ and $\mathrm{REE}$ among the three groups. After pair comparison, it was found that there were differences in $\mathrm{VO}_{2}(P=0.013)$ and $\operatorname{REE}(P=0.014)$ between the normal group and the GDM_24 group. After correction by the Bonferroni method, the differences in $\mathrm{VO}_{2}(P=0.040)$ and $\operatorname{REE}(P=0.042)$ were still significant.

The energy metabolism risk analysis of the normal group, GDM_24 group, and GDM_30 group at 11-13 weeks of pregnancy is shown in Table 3. The $\mathrm{VO}_{2}, \mathrm{VCO}_{2}$, and REE of the GDM_24 group were significantly at risk compared with the normal group. An increase of one unit of $\mathrm{VO}_{2}, \mathrm{VCO}_{2}$, and REE increased the risk of GDM_24 in normal pregnant women by $2.4 \%, 3.5 \%$, and $0.4 \%$, respectively, but the risk was no longer significant after adjustment for basic information.

The basic information of 96 subjects at 16-19 weeks of pregnancy is shown in Table 4, including 52 in the normal group, 21 in the GDM_24 group, and 19 in the GDM_30 group. According to the result, in 16-19 weeks of gestation, there is no significant difference between the three, so will not risk analysis. 
The energy metabolism information and differences of the normal group, GDM_24 group, and GDM_30 group at 16-19 weeks of pregnancy are shown in Table 5. There were significant differences in $\mathrm{VO}_{2}$, $\mathrm{VCO}_{2}$, and REE among the three groups. After pair comparison, it was found that there were differences in $\mathrm{VO}_{2}(P=0.024), \operatorname{VCO}_{2}(P=0.027)$ and $\operatorname{REE}(P=0.019)$ between the normal group and the GDM_24 group, and there were differences in $\mathrm{VO}_{2}(P=0.022)$, and REE $(P=0.025)$ between the normal group and the GDM_30 group. However, the differences were no longer significant after correction by the Bonferroni method.

The energy metabolism risk analysis of the normal group, GDM_24 group, and GDM_30 group at 1619 weeks of pregnancy is shown in Table $6 . \mathrm{VO}_{2}, \mathrm{VCO}_{2}$, and REE in the three groups were significantly riskier than those in the normal group. Each additional unit of $\mathrm{VO}_{2}, \mathrm{VCO}_{2}$, and REE increased the risk of GDM_24 in normal pregnant women by $2.3 \%, 3.4 \%$, and $0.3 \%$, respectively. Normal pregnant women had an increased risk of GDM_30 by $2.1 \%, 2.6 \%$, and $0.3 \%$, respectively.

\section{Discussion and conclusion}

The increased energy demands of the growing fetus are explained by changes in metabolism that occur during pregnancy. From the metabolism point of view, the pregnant woman anabolism and catabolism by two clearly defined in different periods. The first half of pregnancy is characterized by an anabolic state, storage of energy and nutrients. In this state, there is a decrease in net fat storage and endogenous fat oxidation in the mother $[9,10]$. This study found that the risk of GDM 30 was seen at 16-19 weeks of pregnancy compared with 11-13 weeks of pregnancy. This may be due to the different pathogenesis of GDM_24 and GDM_30. So, it makes sense to differentiate GDM by diagnosis time. At each pregnancy stage, there are different differences in energy metabolism between the normal group and the sick group, which may be related to the metabolic regulation of the normal and sick pregnant women. It may be meaningful to add energy metabolism parameters to the related studies of GDM. Later, more data will be added to explore the results in detail.

\section{Acknowledgments}

This research was funded by the National Key R\&D Program of China (2019YFC0119700), Bill \& Melinda Gates Foundation (OPP1148910), and Beijing Science and Technology Project (Z161100000116005), Intelligent Physiological Measurement and Clinical Translation, Beijing International Base for Scientific and Technological Cooperation.

\section{Conflict of interest}

None to report.

\section{References}

[1] American Diabetes Association, Diagnosis and classification of diabetes mellitus. Journal of Diabetes Care. 2013, 36(Suppl 1): S67-S74.

[2] Metzger BE, Gabbe SG, Persson B, et al. International association of diabetes and pregnancy study groups recommendations on the diagnosis and classification of hyperglycemia in pregnancy. Diabetes Care. 2010; 33(3): 676-682.

[3] Akgöl E, Abuşoğlu S, Deniz Gün Faik et al. Prevalence of gestational diabetes mellitus according to the different criterias. Turk J Obstet Gynecol, 2017; 14(1): 18-22. 
[4] Li MF, Ma L, Yu TP, et al. Adverse maternal and neonatal outcomes in pregnant women with abnormal glucose metabolism. Diabetes Research and Clinical Practice. 2020; 161: 108-85.

[5] Barbour LA. Metabolic culprits in obese pregnancies and gestational diabetes mellitus: big babies, big twists. Diabetes Care. 2019; 42(5): 718-726.

[6] Benhalima K, Crombrugge PV, Moyson C, et al. Characteristics and pregnancy outcomes across gestational diabetes mellitus subtypes based on insulin resistance. Diabetologia. 2019; 62(11): 2118-2128.

[7] Stevenson PH. Calculation of the body2surface area of Chinese. Chin J Physiol, Report Series. 1928; 1: 13-24.

[8] Frayn KN. Calculation of substrate oxidation rates in vivo from gaseous exchange. J Appl Physiol Respir Environ Exerc Physiol. 1983; 55(2): 628-34.

[9] Butte NF. Carbohydrate and lipid metabolism in pregnancy: normal compared with gestational diabetes mellitus. The American Journal of Clinical Nutrition. 2000; 71(5): 1256S-1261S.

[10] Flavien D, Giza SA, Tianna K, et al. Altered maternal and placental lipid metabolism and fetal fat development in obesity: Current knowledge and advances in non-invasive assessment. Placenta. 2018; 69: 118-124. 